Revista de la red interuniversitaria de estudios sobre las literaturas rioplatenses contemporáneas en Francia

19 | 2018

La rebelión de los hijos: el judaísmo en la literatura latinoamericana contemporánea entre tradición y asimilación

\title{
La seducción del crítico
}

\section{Mario Cámara}

\section{(2) OpenEdition}

\section{Journals}

Edición electrónica

URL: http://journals.openedition.org/lirico/6798

DOI: $10.4000 /$ lirico.6798

ISSN: 2262-8339

Editor

Réseau interuniversitaire d'étude des littératures contemporaines du Río de la Plata

Referencia electrónica

Mario Cámara, «La seducción del crítico », Cuadernos LIRICO [En línea], 19 | 2018, Publicado el 12 diciembre 2018, consultado el 24 septiembre 2020. URL : http://journals.openedition.org/lirico/6798 ; DOI : https://doi.org/10.4000/lirico.6798

Este documento fue generado automáticamente el 24 septiembre 2020

\section{c) (i) (9)}

Cuadernos LIRICO está distribuido bajo una Licencia Creative Commons Atribución-NoComercial-

SinDerivar 4.0 Internacional. 


\section{La seducción del crítico}

\section{Mario Cámara}

\section{REFERENCIA}

Panesi, Jorge. La seducción de los relatos. Crítica literaria y política en la Argentina,Buenos Aires: Eterna Cadencia, 2018, 320 páginas. 
1 En el prólogo que da comienzo a $L a$ seducción de los relatos. Crítica literaria y política en la Argentina (2018), su autor, Jorge Panesi, nos advierte que la crítica no se produce en el vacío. Panesi busca hacer visible, a través de este enunciado, la condición laboral del crítico, que no es otra que su tarea docente en una universidad. En ese entrelugar, el profesor, el crítico, va construyendo sus lecturas. Este recordatorio, que no pretende convertirse en un dictamen bourdiano, es, probablemente, una estampa fidedigna del propio Panesi. En efecto, su nombre se encuentra indiscutiblemente asociado a la carrera de Letras de la Universidad de Buenos Aires, en donde tuvo a cargo la cátedra de Teoría y Análisis Literario en un momento en que la teoría literaria vivía su momento áureo.

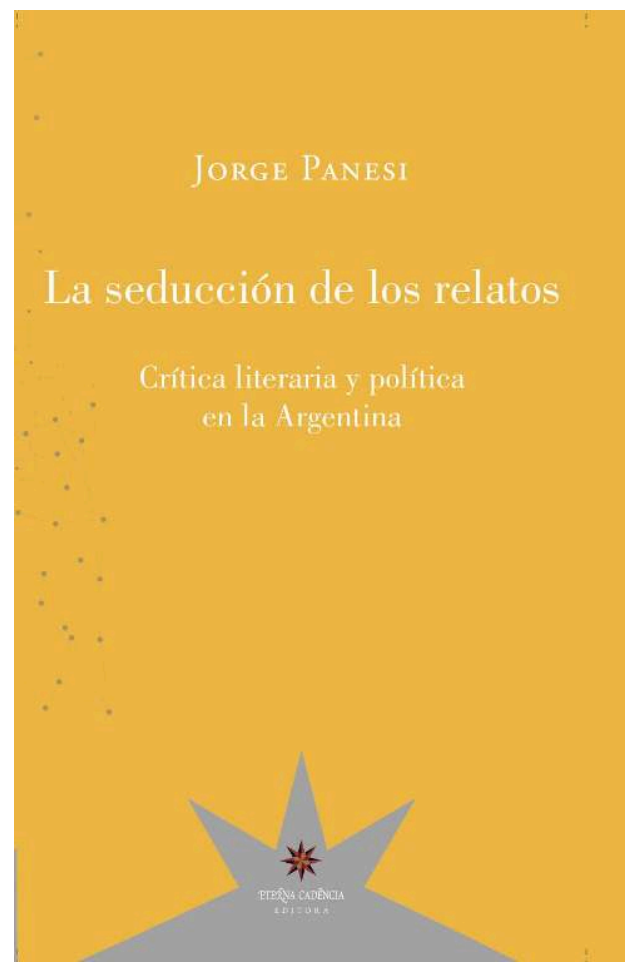

2 La seducción de los relatos es su tercer y

hasta el momento último libro, luego de una larga pausa sin publicar. Sus anteriores libros habían sido Críticas (2000) y Felisberto Hernandez (1993). Como señala el propio Panesi, también en el prólogo, carga con el "remordimiento de haber escrito poco". A modo de compensación, lo primero que puede advertir el lector es que La seducción de los relatos plantea un amplio recorrido pautado por seis secciones. Panesi define su libro como un ejercicio de recopilación de artículos cuyo trasfondo es su propia vejez. La idea de testamento, nos comunica, acecha por lo tanto cada una de sus páginas. Es difícil confirmar el carácter testamentario, esperemos que continúe publicando, pero sí se puede comprobar que este conjunto de ensayos exhibe una serie de preocupaciones e insistencias que reconstruyen una trayectoria intelectual.

La primera parte del libro se titula "Discusiones" y en términos generales los artículos que la componen se focalizan en auscultar el espacio de la crítica argentina desde una perspectiva que busca mapear el presente, sus modos de funcionamiento y su frágil sobrevivencia, sin dejar de hilvanar tradiciones y configuraciones pasadas. El lugar de la polémica, su emergencia o su ausencia, es uno de los ejes que regula los dos primeros textos, "Acerca de una frase desdichada y sobre la desdicha de no tener polémicas" y "Polémicas ocultas". Más allá del recorrido descriptivo, que atraviesa desde las publicaciones El Rodaballo a Punto de Vista pasando por El Ojo Mocho, Panesi se manifiesta a favor de la polémica aunque considere que no se las puede inventar "porque en su azar son estrictamente, culturalmente, necesarias" (33). Mientras que, completará en el segundo de los textos mencionados, "es la política más o menos mediada, o impuesta sin mediaciones para acallar el disenso, la que en la cultura argentina regula los marcos de aparición y desaparición de las polémicas" (37). Panesi se revela aquí como un hábil y elegante polemista, pues apuntando contra quienes se lamentan del fin de las polémicas, Beatriz Sarlo por ejemplo, él mismo propone la suya. Probablemente haya que sumar a esta serie el tercer texto de la sección, "Los que se van, los que se quedan 
(apuntes para una historia crítica de la crítica argentina)", texto en el que recorre el viaje académico, resultado del exilio o de la búsqueda de nuevos horizontes laborales. En esta lectura reinscribe, o al menos solicita hacerlo, el trauma del exilio y también las polémicas que se fueron tejiendo alrededor de la elección entre irse o quedarse, como por ejemplo la que protagonizaron Julio Cortazar y Liliana Heker. Como si, una vez más, la polémica, en sus emergencias, modulara las posiciones intelectuales y el ejercicio de la crítica.

4 La segunda sección del libro lleva por título "Pasiones de la historia". Panesi aborda aquí tres historias de la literatura argentina, la Historia social de la literatura argentina, dirigida por David Viñas, la Historia crítica de la literatura argentina, de Noe Jitrik y la Breve historia de la literatura argentina, de Martín Prieto, para detectar la emanación de un pathos, una pasión de escritores y críticos por la historia de la literatura, o quizá, de un modo más general, una pasión por la historia a secas. En el conjunto de estos ensayos es donde se revela con mayor claridad un cierto modo de leer de Panesi, un modo que no deja de enhebrar pacientemente los debates, las polémicas, los traumas que la literatura argentina ha ido experimentando a lo largo del siglo XX, como por ejemplo el legado de la revista Contorno, que resuena en las historias literarias de quienes fueran integrantes de aquella publicación, Viñas y Jitrik; o la tradición crítica en la que se inscribe Prieto, que incluye a Josefina Ludmer, Nicolás Rosa o Sandra Contreras, entre otros. Ese modo de leer indica, además, la propia pasión de Panesi por la historia y un exhaustivo conocimiento de las publicaciones e instituciones que fueron configurando eso que llamamos literatura y crítica argentinas.

5 La tercera sección nos aproxima al Panesi más familiar, al menos para quienes tuvimos la suerte de cursar Teoría y análisis literario con él como profesor. Se trata del Panesi lector de literatura. La sección desgrana una selección heterogénea, que incluye a Silvina Ocampo, a Mario Bellatin, a Luis Gusmán y a César Aira. Dispersas en los ensayos, entre agudos y renovadores análisis, Panesi desgrana algunas definiciones de lo que entiende por literatura, como cuando afirma, para referirse a Mario Bellatin, que "el arte o la literatura no explican el universo; las narraciones que circulan en las comunidades artesanales de las que nos habla Benjamin se alejan de la explicación como si fuese ese mal que efectivamente habría destruirlas. El arte de la narración no consiste en la trapisonda de construir espejos explicativos, sino en montar mundos paralelos cuyas relaciones con el mundo cotidiano (esa madeja de convenciones) es, a la vez, evidente, imposible y tangencial" (159). En esa relación paradójica entre literatura y realidad, o entre literatura y política, inscribirá a Villa, la novela de Luis Gusmán. Ambientada entre el período final del gobierno peronista de los setenta y el inicio de la última dictadura, la historia narra la trayectoria del personaje Villa, un oscuro chofer del Ministerio de Bienestar Social durante el comando de José Lopéz Rega. Sin embargo, en lugar de acudir a explicaciones de tipo histórico, el terror se instala en la novela como resultado de la construcción narrativa de dispositivos, sistemas, jerarquías infinitas y máquinas. El rechazo a las causalidades históricas, por último, reaparece en el análisis de Un episodio en la vida del pintor viajero, de Aira, cuando sostiene que "tanto la narración como la pintura o el arte en general siempre son la perplejidad suplementaria ante todas las explicaciones" (184).

6 La cuarta sección aborda la obra de tres poetas sobre los cuales Panesi ya había escrito, Néstor Perlongher, Arturo Carrera y Tamara Kamenszain. Lo que emerge aquí en primer plano es una atención sobre la lengua, una lengua que, nos informa Panesi, en el 
caso de Perlongher se ha vuelto loca. Esta condición le permite establecer una conexión problemática entre poesía y política. Si la política bordea el mito, lo usa y lo trabaja para alcanzar su eficacia, la poesía de Perlongher apuesta al delirio como un anti-mito que se construye con la misma sustancia que emplea la acción política pero para destruirla desde adentro, con su propio mecanismo hipertrofiado, sexualizado, lumpenizado. El delirio, también podríamos decir en clave deleuziana, las líneas de fuga, no estratifican ni forman centro, como sí pretende hacerlo la política. En el ensayo dedicado a Arturo Carrera, que aborda El vespertillo de las parcas, la dimensión de la lengua pasa de la locura al murmullo. En ese poemario familiar, lo que destaca Panesi son los "ruiditos", los "bisbiseos", o el "blablablá", porque la poesía siempre ocupa un borde lacunar, un extremo que consigue desfamiliarizar los recuerdos familiares.

7 La penúltima sección se titula "Retratos", pero también podría llamarse "Homenajes". Allí desfilan David Viñas, una presencia constante a lo largo de todo el libro, Ana María Barrenechea, Nicolás Rosa, Josefina Ludmer, Silvia Molloy y Alberto Giordano. Se trata, en algunos casos, de textos que surgieron a partir de intervenciones públicas, como la presentación de la reedición de Literatura argentina y realidad política de David Viñas o la laudatio en el Honoris Causa entregado por la Universidad de Buenos Aires a Josefina Ludmer en 2010. En esta serie, leyendo a sus colegas, Panesi piensa, una vez más, en el trabajo de la crítica. En el artículo dedicado a Nicolás Rosa, por ejemplo, encontramos un elogio de lo ilegible, que es definido no como un accidente en el camino iluminista de la crítica, o una insuficiencia que otras lecturas llenarían finalmente con su luz. "Esa sombra, nos dice Panesi, esa ceguera de la lectura, está en el mismo ojo y en la mirada que recorre la página" (252). o la defensa del "no entender" con la que comienza la laudatio de Josefina Ludmer. Si la literatura y el arte, como hemos visto, cortan amarras con las lógicas explicativas de la Historia, colocándose en un lugar excéntrico o suplementario, exterior o "delirante", la crítica, sugiere Panesi, no debería pretender reestablecer algún tipo de inteligibilidad, sino más bien acompañar esos lenguajes desquiciados, contagiarse, ella misma, de ese carácter excéntrico, tal como lo enuncia y lo exige en su ensayo dedicado a la poesía de Perlongher.

El final del libro, la sexta sección, contiene un único ensayo dedicado a Borges, titulado "Borges, da capo", en el que Panesi parece concretar un ajuste de cuentas con las posturas políticas de Borges en torno al peronismo. Luego de recorrer su amor por orilleros y cuchilleros, sus iniciales posturas populares, Panesi sigue la deriva antiperonista de Borges, su empecinamiento a través de los años. Como si en su antiperonismo, concluye, anudando vida y literatura, Borges, cual compadrito, hubiera encontrado en Perón a su contrincante privilegiado.

9 La configuración de eso que conocemos como crítica literaria, con sus modalidades institucionales y parainstitucionales de funcionamiento, las relaciones excéntricas de la literatura con la política y con la Historia y, por último, las políticas de la crítica, constituyen los tres grandes ejes de La seducción de los relatos. Pero hay algo más: como buen profesor, Panesi nos enseña cómo acercarnos al texto literario, cómo hacer hablar la densidad histórica de las polémicas que, de modo recurrente, atraviesan a la crítica literaria, y cómo escuchar las lenguas disruptivas de la poesía. 


\section{AUTORES}

\section{MARIO CÁMARA}

CONICET/Universidad Nacional de las Artes /Universidad de Buenos Aires

mario_camara@hotmail.com 